Voix et Images

volxetimages

\title{
Turgeon, Beauchemin, Tremblay et les autres...
}

\section{André Vanasse}

Volume 7, numéro 2, hiver 1982

Michel Tremblay

URI : https://id.erudit.org/iderudit/200333ar

DOI : https://doi.org/10.7202/200333ar

Aller au sommaire du numéro

Éditeur(s)

Les Presses de l'Université du Québec

ISSN

0318-9201 (imprimé)

1705-933X (numérique)

Découvrir la revue

Citer cet article

Vanasse, A. (1982). Turgeon, Beauchemin, Tremblay et les autres... Voix et Images, 7(2), 417-419. https://doi.org/10.7202/200333ar d'utilisation que vous pouvez consulter en ligne.

https://apropos.erudit.org/fr/usagers/politique-dutilisation/ 


\title{
Roman
}

\section{Turgeon, Beauchemin, Tremblay et les autres...}

\author{
par André Vanasse
}

Gilles Marcotte avait raison de dire, dans sa chronique de l'Actualité de septembre dernier, que, cette année, la production romanesque s'avérait d'une indéniable qualité. De nouveaux auteurs ont fait une entrée remarquée tandis que certains anciens confirmaient leur talent.

S'il n'est pas toujours de bon ton de parler des prix littéraires, cette fois-ci on peut faire exception. Pour le Gouverneur, La Première Personne ${ }^{1}$ de Pierre Turgeon, un récit qui se déroule à Los Angeles. Un roman policier comme seul un Québécois peut le déconstruire. II faut croire que notre viscéral refus de l'autorité contamine, dans la sphère du littéraire, les lois du genre. Cela expliquerait sans doute pourquoi nos Simenon procèdent soit selon le registre du dérisoire, comme l'on fait récemment Papartchu Dropaôtt et Oslovik (deux pseudonymes qui en disent long sur le contenu de leurs romans), soit selon celui de la sourde contestation laquelle se manifeste de la façon la plus bête : le lecteur ne sait plus qui sont les bons et qui sont les méchants! Dans ce dernier genre, Hubert Aquin nous a révélés à nous-mêmes grâce à Prochain épisode, son génial roman policier raté. Pierre Turgeon poursuit dans la même veine. Maîtrisant magnifiquement son écriture, il nous livre l'histoire d'un héros branché sur computer, sorte de surhomme à pitons, nouveau détective électronicien. Or ce supercrack se révèle, au bout du compte, aussi démuni que vous et moi. En somme, un pauvre petit Québécois qui se sera pris, encore une fois, pour quelqu'un d'autre.

Parmi les finalistes du prix du Gouverneur, on ne peut passer sous silence Les Masques ${ }^{2}$ de Gilbert LaRocque. J'imagine que le jury a longuement délibéré car ce roman, dur et violent, à propos d'un enfant noyé et d'un couple à la dérive, est une très grande réussite. Serge d'entre les morts nous avait révélé l'immense talent de LaRocque. Les Masques nous le confirme de magistrale manière. Mais il aura joué de malchance dans cette course au prix : son écriture, agressante au possible et parfois même carrément répugnante, l'aura desserví. Dommage parce qu'il méritait au- 
tant que Turgeon de recevoir une consécration pour l'œuvre qu'il a accomplie.

Michel Tremblay, pour sa part, a décroché le prix France-Québec pour Thérèse et Pierrette à l'école des Saints-Anges ${ }^{3}$. Je ne comprends pas pourquoi cette chronique m'a un tantinet deçu par rapport à La Grosse Femme... Pourtant on y retrouve tous les eléments qui ont rendu Michel Tremblay célèbre. Plus particulièrement ce mélange du quétaine québécois et de la Grèce antique (cf. les chceurs des Belles-Sœurs, les trois Parques de La Grosse Femme) qui donne à ses écrits ce ton si particulier. Cette fois-ci Tremblay pousse encore plus loin. II introduit le "carnavalesque " (au sens où Bakhtine l'entend) dans sa description de la procession de la Fête-Dieu. C'est à suivre.

Du côté des moins expérimentés, il faut signaler Robert Lalonde, prix Robert Cliche, avec La Belle Épouvante ${ }^{5}$. Deux réactions possibles devant ce texte-confession: ou le lecteur se laisse prendre par le ton brillant (Lalonde affectionne Ducharme, c'est évident), accrocheur, tendre, et «interpelleur", ou encore il condamne le texte au nom des défauts de ses qualités en le traitant de détestable numéro de narcissisme et de cabotinage. Chose certaine, pas de demi-mesure devant cette histoire d'amour à n'en plus finir où seule la voix mâle du couple se fait entendre.

Mais il n'y a pas que les prix. Je m'en voudrais de passer sous silence Le Matou ${ }^{5}$ de Yves Beauchemin. Bien sûr les inconditionnels de la modernité en feront des gorges chaudes. Le Matou est, sans conteste, servi à l'ancienne. II offre cependant cette qualité d'être un pur chef-d'cuvre. Impossible de décrocher devant cette histoire d'un jeune héros (Florent Boissonneault) du plateau Mont-Royal (eh oui! Comme Michel Tremblay) dont les aventures et surtout les mésaventures ne cessent de nous tenir en haleine. Tout cela à cause d'un certain Ratablavasky qui, à mesure que le roman progresse, ressemble de plus en plus à Méphistophélès réincarné en la personne de cet étrange Slave aux pieds malodorants...

En fait Beauchemin renoue avec la tradition des feuilletonnistes (Balzac, Sue, Dostoïevski) et nous propose une aventure à épisodes qui pourrait faire l'objet d'une adaptation télévisuelle à Radio-Québec où Yves Beauchemin travaille depuis quelques années. Peut-être que Le Matou nous divertirait des platitudes qu'on y entend depuis longtemps. Cela se peut. Bien qu'il faille être prudent dans ce genre de métamorphose : un bon romancier ne fait nécessairement un bon téléromancier. Quoi qu'il en soit, les naïfs, les idéalistes, bref les gens qui aiment lire pour lire prendront un indéniable plaisir à dévorer page à page ce récit aux innombrables rebondissements.

C'est un plaisir d'une toute autre nature que connaîtront les lecteurs (trices) de Ma Fille comme une amante ${ }^{6}$ de Julie Stanton. Ce court texte d'une centaine de pages intéresse d'abord comme document. Julie Stanton ne maîtrise pas suffisamment son écriture (une journaliste n'est pas 
nécessairement écrivain) mais ce qu'elle a à nous dire concerne la génération des femmes d'aujourd'hui, celles qui ont osé (chose impensable autrefois) quitter mari et enfants pour aller faire peau neuve et renouer avec la vie. Ma Fille comme une amante fait le bilan sur une mère "drop out", nous renseigne sur son existence de mère redevenue célibataire et nous montre bien que sa destinée ressemble finalement (une fois vaincu l'oppressant sentiment de culpabilité de la mère fugitive) à celle de tout homme divorcé. Alors quoi? Alors il fallait le savoir et savoir aussi que la mère peut, après les souffrances de la séparation, retrouver sa fille "comme une amante". Un livre touchant et qui en scandalisera quelques-uns.

Bien sûr, il faudrait aussi parler de Louis Caron, André Major, Jacques Benoît. Ce sera pour la prochaine chronique.

\footnotetext{
1. Pierre Turgeon, La Première Personne, Montréal, Ed. Quinze, 1981, 155 p.

2. Gilbert LaRocque, Les Masques, Montréal, Ed. Québec-Amérique, 1981, $191 \mathrm{p}$.

3. Michel Tremblay, Thérèse et Pierrette à l'école des Saints-Anges, Montréal, Leméac, 1981, 368 p.

4. Robert Lalonde, La Belle Épouvante, Montréal, Ed. Quinze, Prix Robert Cliche, 1981, $155 \mathrm{p}$.

5. Yves Beauchemin, Le Matou, Montréal, Ėd. Québec-Amérique, 1981, 583 p.

6. Julie Stanton, Ma fille comme une amante, Montréal, Ed. Leméac, 1981, $99 \mathrm{p}$.
} 